\title{
Fat Embolism Syndrome
}

\author{
Mahmoud Fenire MD
}

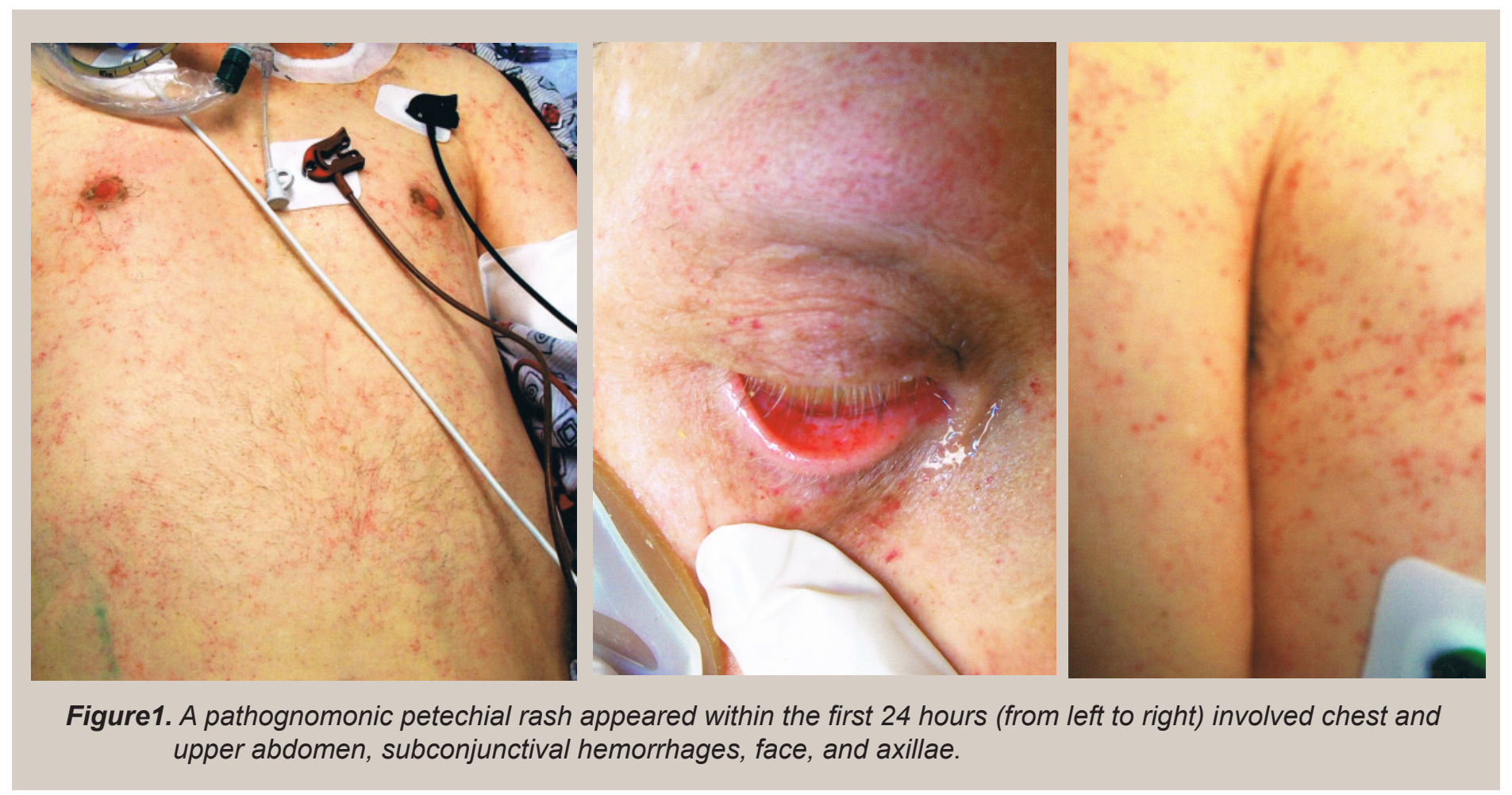

A 59-year-old man with Down's syndrome sustained bilateral femoral neck fractures after a fall and underwent bilateral hemiarthroplasties within six hours from his injury. He developed respiratory distress and decreased level of consciousness while in the post-anesthesia care unit and had to be reintubated within an hour after his extubation. Over the next 24 hours, he developed skin rash shown in Figure 1. Despite supportive care, he remained unresponsive,

Corresponding author: Mahmoud Fenire MD Contact Information: Mahmoud.fenire@ttuhsc.edu DOI: 10.12746/swrccc 2014.0205.057 developed multiorgan failure, and eventually died.

Fat embolism occurs in nearly all patients (> $90 \%$ ) with bone fractures during orthopedic prosthesis procedures and rarely occurs in other pathologic conditions ${ }^{1}$. Approximately 3 to $4 \%$ of these patients develop the classical triad of the fat embolus syndrome (FES), which consists of petechial hemorrhages (Figure 1), respiratory distress (Figure 2), and cerebral abnormalities (Figure 3); most patients remain asymptomatic ${ }^{1}$.

The clinical pattern of this syndrome has a bimodal distribution; some patients clearly demonstrate a fulminant course with the onset of symptoms within 
12 hours of injury. Most patients have a more subacute course and manifest symptoms 24 to 72 hours after injury ${ }^{2}$. Bulger et al reported that only $33 \%$ of patients in a 10-year review retrospective study of FES had documented petechiae ${ }^{2}$. The most promi- nent manifestation of the syndrome is acute hypoxia². Even when lung injury is obvious, it may be attributed to infection, aspiration, or traumatic ARDS, rather than to $\mathrm{FES}^{3}$. Treatment of FES is supportive care.

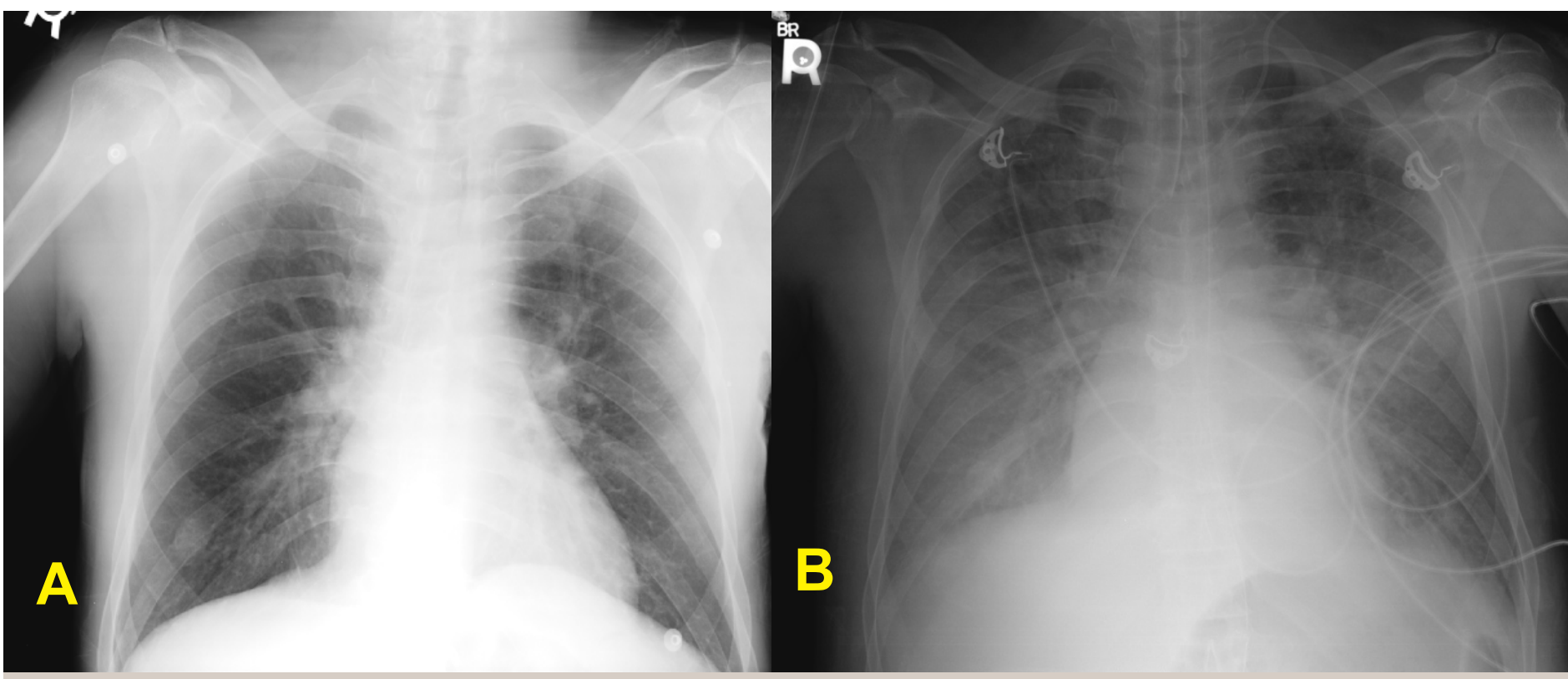

Figure 2. Chest $X$ ray on admission $(A)$ and two days later $(B)$ reveals diffuse bilateral infiltrates along with $\mathrm{PaO2}$ :FiO2 $<200 \mathrm{mmHg}$ suggestive of ARDS

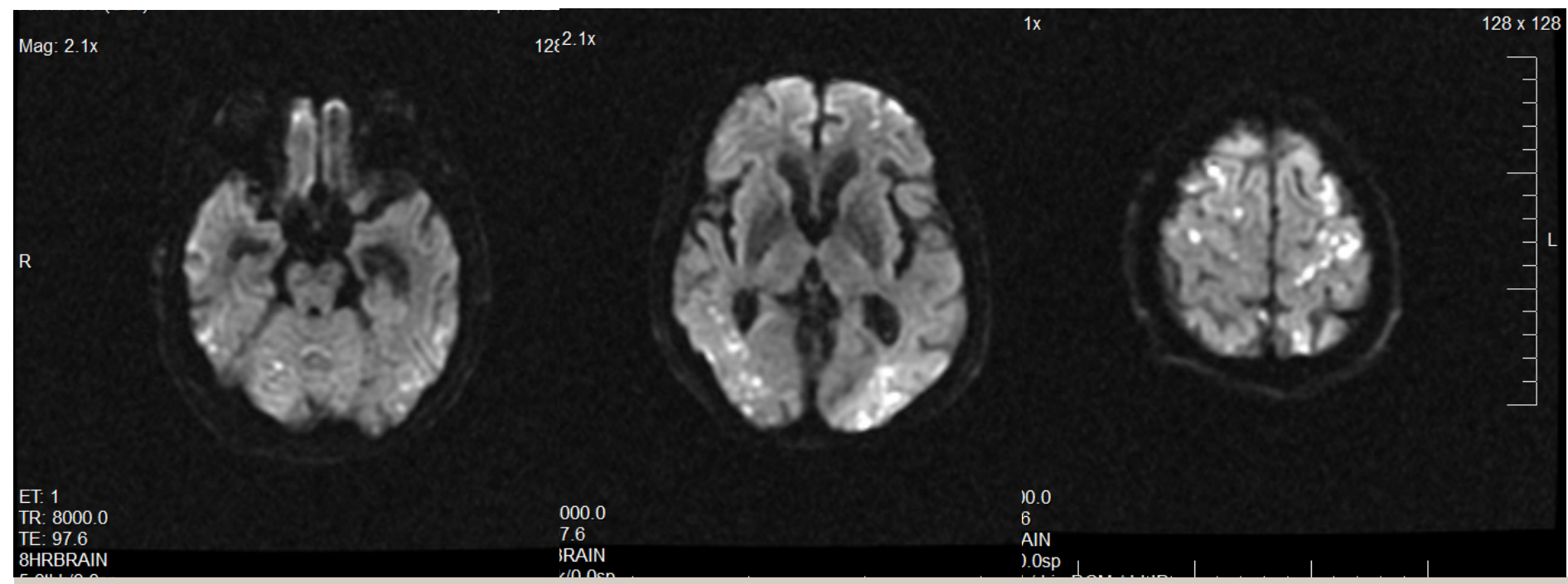

Figure 3. MRI brain - diffusion - weighted images show numerous punctate foci of high signal intensity - cortical and subcortical secondary to fat emboli. 
- The patient's caregiver and power of attorney signed consent for publication of photos identifying patient for educational purposes.

Received: $11 / 4 / 2013$

Accepted: $12 / 4 / 2013$

Reviewers: Kenneth Nugent MD

Published electronically: 1/16/2014

\section{References}

1. Malagari K, Economopoulo N, Stoupis C, Daniil Z, Papiris S, Müller NL, Kelekis D. High-resolution CT findings in mild pulmonary fat embolism. Chest 2003; 123(4):1196-1201. doi:10.1378/chest.123.4.1196

2. Bulger EM, Smith DG, Maier RV, Jurkovich GJ. Fat embolism syndrome, a 10-year review. Arch Surg 1997;132(4):435439. doi:10.1001/archsurg.1997.0143028010901

3. Christie J, Robinson CM, Pell AC, McBirnie J, Burnett R. Transcardiac echocardiography during invasive intramedullary procedures. J Bone Joint Surg Br 1995 May; 77(3):450-5. 